\title{
Construction and Empirical Study of Evaluation Index System on the Informationization of Transportation in Dalian City
}

\author{
Yunhua Sun ${ }^{1,2, a}$, Yunfei $A i^{1, b}$ \\ ${ }^{1}$ China Transport Telecommunications \& Information Center, Beijing, China \\ ${ }^{2}$ Institute of Geographic Sciences and Natural Resources Research, CAS, Beijing, China \\ ayunhua07@163.com, baiyunfei@cttic.cn
}

Keywords: informationization of transportation; evaluation index; entropy weight method; Dalian City

Abstract. Traffic informationization is an important carrier and means to realize intelligent transportation, and also a key factor to promote the strategy of a powerful nation in transportation. According to the content and characteristics of the evaluation on the development of transportation informatization, this paper establishes the development of Dalian's transportation informatization from four aspects including the comprehensive perception of information, the efficient and convenient integrated service, traffic information application system and traffic information standard construction. Entropy method is used in this paper to measure the development level of traffic informationization in Dalian. Analysis shows that the rapid development of Dalian's urban traffic informatization has more obvious stage characteristics. From 2011 to 2017, Dalian's traffic informatization construction has entered the general stage of development from the initial stage.

\section{Introduction}

The rapid development of information technology has a huge impact on all areas of society and people's living habits. In the past ten years, the traffic information gradually emerged and became the focus of scholars at home and abroad ${ }^{[1,2]}$. Traffic informationization not only uses information technology to reform transportation infrastructures, delivery equipment and management tools, but also covers many challenges that the government faces in such fields as traffic planning, public service, improvement of livelihood and economic development in the information age $\mathrm{e}^{[3]}$.

Scientific and accurate objective evaluation of the state of urban traffic information development must rely on the quantitative evaluation index system. In view of the complexity of urban traffic information construction and the wide range of contents involved, it is necessary to comprehensively evaluate the construction of urban traffic information according to the characteristics and objectives of urban traffic information construction. Therefore, the establishment and promotion of comprehensive evaluation index system of urban transportation informatization has laid a foundation for promoting the scientific decision-making of green travel and building a intelligent city, which has high practical value and theoretical significance.

\section{Construction of Dalian City Traffic Information Evaluation Index System}

Based on the basic principles of evaluation on the urban traffic information development, referring to the development report of China's traffic informatization and the standard system of traffic information released by China's Ministry of Transport, this paper establishes evaluation index system of urban transportation informationization from 5 aspects: comprehensive information perception, data collection and sharing, efficient and convenient integrated services, open and sharing of information resources, and strong development environment security. This indicators system set four first-level indicators, 13 second-level indicators, 16 third-level indicators, as shown in Table 1.

The evaluation index system of urban traffic informatization constructed in this paper includes five major factors of urban traffic informatization and comprehensively examines the benefits of urban 
traffic informatization, especially considering the development goals and overall characteristics of urban traffic informatization at the present stage. It has the following advantages:

(1) Clear logic

The hierarchy of the indicator system is clear, well-structured and has strong operability and feasibility. The first level indicator is the directional focus of urban traffic information construction and development. The second and third level indicators are more operational, and belonging to the application of urban transportation informatization. They are easy to acquire and evaluate .

(2) Has a certain degree of adaptability and scientific

The city traffic informationization index system constructed in this paper is a universal framework. According to the characteristics of traffic development and the principle of easy-availability of data, the second-level indicators are embodied and extended to 32 third-level indicators. Among them, there are 25 quantitative third-level indicators, accounting for $78.13 \%$ of the entire evaluation index system; and 8 qualitative three-level indicators, accounting for $24.87 \%$ of the entire evaluation index system. Using expert scoring method to determine the value of qualitative indicators (expert scoring of reference are urban traffic information development status in 2000). Subjective and objective combination of methods, on the one hand can guarantee the objectivity of the evaluation index system, on the other hand you can clear the purpose of the index system. Quantitative indicators and qualitative indicators combine to build the evaluation index system to fully reflect the actual construction of urban traffic information and development.

Table 1 Evaluation Index System of Urban Transportation Industry Informatization Development Level

\begin{tabular}{|c|c|c|c|}
\hline Target layer & First-level indicator & Second-level indicator & Third-level indicator \\
\hline \multirow{16}{*}{$\begin{array}{l}\text { The city traffic } \\
\text { informationization }\end{array}$} & \multirow{7}{*}{$\begin{array}{l}\text { The comprehensive perception } \\
\text { of information }\end{array}$} & \multirow{2}{*}{$\begin{array}{c}\text { Transportation Infrastructure } \\
\text { Investment }\end{array}$} & $\begin{array}{l}\text { X1--City-level fixed assets investment in } \\
\text { transportation (billion) }\end{array}$ \\
\hline & & & X2--Investment growth rate \\
\hline & & $\begin{array}{l}\text { Comprehensive transportation } \\
\text { passenger terminal construction }\end{array}$ & X3--Number of transport hubs \\
\hline & & \multirow{3}{*}{$\begin{array}{l}\text { Comprehensive traffic monitoring } \\
\text { equipment construction }\end{array}$} & X4--Video surveillance equipment \\
\hline & & & X5--Compliance monitoring equipment \\
\hline & & & X6--Outdoor display screen \\
\hline & & $\begin{array}{l}\text { Traffic signal control equipment } \\
\text { construction }\end{array}$ & X7--The total number of traffic lights \\
\hline & The efficient and convenient & Traffic Information Service Type & X8--Types of traffic information published \\
\hline & integrated service & Traffic Information Service & X9--Type of information distribution method \\
\hline & \multirow{4}{*}{$\begin{array}{c}\text { Traffic Information Application } \\
\text { System }\end{array}$} & E-government system & X10--Number of e-government systems \\
\hline & & Industry Supervision Platform & $\begin{array}{c}\text { X11-Number of industry supervision } \\
\text { platform }\end{array}$ \\
\hline & & Public Travel Service System & X12-Number of public travel service system \\
\hline & & $\begin{array}{l}\text { Traffic Emergency Management } \\
\text { Information System }\end{array}$ & $\begin{array}{l}\text { X13--Number of traffic emergency } \\
\text { management information system }\end{array}$ \\
\hline & \multirow{3}{*}{$\begin{array}{l}\text { Traffic Information Standard } \\
\text { Construction }\end{array}$} & Traffic Policy Standard & $\begin{array}{l}\text { X14--Number of related policies and } \\
\text { standards for traffic informatization }\end{array}$ \\
\hline & & Major transportation planning & $\begin{array}{l}\text { X15--Number of related major planning for } \\
\text { traffic informatization }\end{array}$ \\
\hline & & Traffic research & $\begin{array}{c}\text { X16--Number of related research for traffic } \\
\text { informatization }\end{array}$ \\
\hline
\end{tabular}

\section{Evaluation of Development Level on Traffic Informationization in Dalian}

\section{(1)Overview of Traffic Information Construction in Dalian City}

During the "Twelfth Five-Year Plan" period, the investment of Dalian's transportation system continuously increased and played an active role in promoting integrated transportation, intelligent transportation, green transportation, safe transportation, and livelihood transportation. The Dalian Traffic Management Bureau promoted the development and application of intelligent traffic information systems, and built 53 systems for e-government, industry supervision, travel services, and safety and emergency services, and 11 other systems are being implemented. The results of informatization construction have been initially apparent. Although Dalian's traffic informatization construction has made considerable progress, the economic and social development in Dalian has been undergoing rapid development. The pace of urbanization and motorization has been further accelerated, 
and the contradiction between transportation needs and the urban environment has become increasingly prominent.

\section{(2)Measurement of Dalian Traffic Information Development Level}

The measurement of the development level of urban traffic informatization belongs to the category of multi-attribute decision-making, so it can consider the use of AHP, DEA, gray system theory, entropy method and other analysis methods ${ }^{[4]}$. This paper uses entropy method to measure the development level of traffic informationization in Dalian. On the one hand, the entropy-weighted method can evade the subjectivity of indicators in the evaluation process, and on the other hand, it helps to deal with the dimensional differences in the indicator system. The entropy weighting method is calculated as follows: First, all indicator data are standardized. The pre-processed value of the zero value after normalization is replaced by 0.000001 , and the effect of this substitution on the final result is negligible. Then the information entropy, the information entropy redundancy and the entropy weight of the indicator are calculated, and the index weights and the standardized index values are simply weighted linearly. Formulated as follows:

$$
P_{i}=\sum_{j=1}^{n} X_{i j}^{\prime} R_{j}
$$

Among them, $P_{i}$ represent the comprehensive index of urban traffic information development, $X_{\mathrm{ij}}$ represent the value of assessment indicators for traffic information development in the $i^{\text {th }}$ city, the $j^{\text {th }}$ evaluation year after standardized processing. $R_{j}$ represent the weight of the $j^{\text {th }}$ indicator. The larger the difference between the values on the same indicator, the smaller the entropy value and the greater the weight, indicating that this indicator can provide more decision information.

\section{(3)Result analysis}

Based on the informatization development model proposed by Harvard University professor Richard Nolan in the 1980s, the traffic informationization of Dalian City developed rapidly during the "12th Five-Year Plan" period. From 2011 to 2017, Dalian's urban traffic informatization development index rose from 0.13 to 0.5 , which is basically in a rising trend, with obvious phased characteristics. The first stage: from 2011 to 2012, the traffic informationization construction in Dalian was at the initial stage of informationization. At this stage, the relevant departments have only just started the preliminary investigation and research work for the planning of transportation informatization. The second phase: from 2013 to 2016, the urban traffic informationization construction was at the popularization stage of informationization. A large number of informatization systems began to gradually go online, resulting in continuous improvement of the informatization index. The third stage: In 2017, the traffic informationization construction of Dalian City was at the stage of informatization control and entered the stage of informatized data management.

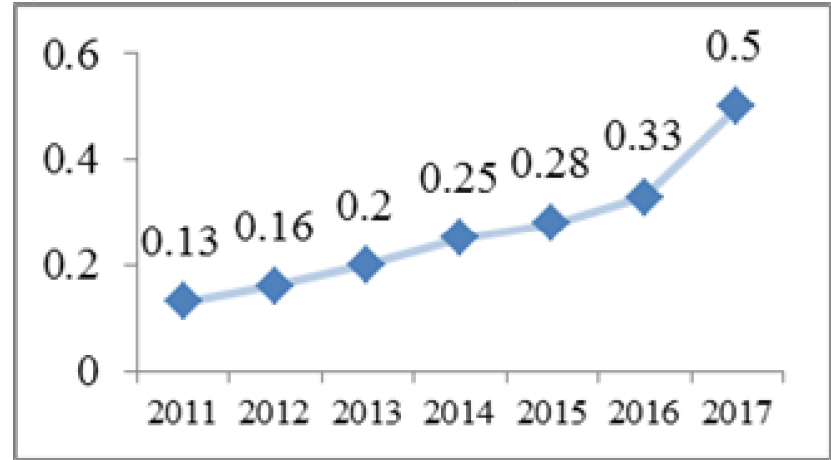

Fig.1 Traffic Informatization Development Index in 2011-2017. 


\section{Conclusions}

This paper draws lessons from the experience of domestic and international traffic informatization evaluation and combines with the practice of China's traffic informatization construction to construct a total of 13 indicators including 4 aspects including comprehensive information perception, efficient and convenient comprehensive service, application of traffic informatization system, and construction of traffic informatization standards. The evaluation index system for the development of urban traffic informatization is based on the example of Dalian City and an empirical analysis of the index system using entropy weight method. From the actual measurement of the development level of urban traffic informationization in Dalian from 2011 to 2017, the index system constructed in this paper reflects the practical situation of urban traffic informatization construction. Analysis shows that the rapid development of Dalian's urban traffic informatization has more obvious stage characteristics. From 2011 to 2017, Dalian's traffic informatization construction has entered the general stage of development from the initial stage.

The comprehensive evaluation of urban traffic information construction is a dynamic process. It must not only reflect the characteristics of China's traffic informatization construction, but also meet the development requirements of intelligent cities $^{[5]}$. It needs to be repeatedly explored and revised in practice, taking into account both scientific and operability can ultimately guide the practice of China's urban traffic informatization construction and contribute to the construction of a smart city. Urban traffic informatization construction is a complex and gradually advancing process. The related projects usually involve high technical level, large investment, long project cycle, and rapid demand changes. At present, all cities have different traffic conditions and transportation informatization goals, and all have more or less a problem that the one-sidedness of traffic informatization is greater than the overall situation, resulting in a low utilization rate of resources and an ineffectiveness in the construction of transportation informatization. The top priority is to conduct a comprehensive and detailed assessment of the development level of various urban traffic informatization, help traffic management departments and relevant decision-making departments to sort out the problems in the process of urban traffic informatization construction, and to formulate appropriate strategies for the development of urban traffic informatization. The ultimate goal is to promote the comprehensive and balanced development of urban traffic informationization.

\section{Acknowledgements}

This work was financially supported by The National Key Research and Development Program of China(2017YFC0803900), Evaluation of Dalian City's Traffic Information Development Level and Implementation Plan of Intelligent Traffic Construction(DFHZ-20171109) and the China Transport Telecommunication \& Information Center reserve project in 2017 (2017CB05).

\section{References}

[1] Cheewapattananuwong W \& Taneerananon P \& Nakatsuji T. Mitigating Traffic Congestion and Accidents in Thailand with Intelligent Transportation System Technology. Transportation Research Record, 2239. (2011)

[2] Griskeviciute $\square$ Geciene \& Griskevicius. The comparable analysis of the assessment of infrastructure projects on Lithuanian urban and road transport systems. $14^{\text {th }}$ International Conference Transport Means. (2010)

[3] Zhang W, Lu J, Zhang Y. Comprehensive Evaluation Index System of Low Carbon Road Transport Based on Fuzzy Evaluation Method. Procedia Engineering, 137:659-668. (2016)

[4] Zong Gang, Li Tenghaizi. An evaluation index system on the informationization of transportation in mega cities. Wuhan University journal(philosophy \& social sciences). 68(2):102-108.(2015) 
[5] Yang X Y, Zhao X H, Liao Q R. Study on Designing Evaluation Index System in Demonstration Area of Integrated Transport. China Transportation Review, 2015. 